\title{
The influence of obesity and overweight on medical costs: a panel data perspective
}

\author{
Toni Mora • Joan Gil • Antoni Sicras-Mainar
}

\begin{abstract}
This paper estimates the increase of direct medical costs of both severe and moderate obesity and overweight with respect to a normal-weight individual using a two-part generalised linear model and a longitudinal dataset of medical and administrative records of patients in primary and secondary healthcare centres followed up over seven consecutive years (2004-2010) in Spain. Our findings indicate that severe and moderate obesity imposes a substantial burden on the Spanish healthcare system. Specifically, being severely obese is associated with increases in medical costs of $26 \%$ (instrumental variables (IV) estimate, $34 \%$ ) compared to a normal-weight individual. The effects of moderate obesity and overweight are more modest, raising medical costs by $16 \%$ (IV estimate, $29 \%$ ) and $8.5 \%$ (IV estimate, $23 \%$ ), respectively. These changes in costs are slightly higher for those patients below the median age and for the women. Notwithstanding, the effects found in this study are comparatively much lower than that reported for the USA, based basically on a private healthcare system and characterised by a more obese population.
\end{abstract}

Keywords

BMI and obesity

Healthcare costs

Panel data

Two-part models

T. Mora

Universitat Internacional de Catalunya and IEB, 22 Immaculada,

J. Gil

CAEPS, University of Barcelona (UB), Barcelona, Spain

A. Sicras-Mainar

Badalona Serveis Assistencials (BSA), Badalona, Barcelona, 


\section{Introduction}

Obesity is a complex, multifactorial, chronic disease involving genetic, perinatal, and environmental components. Its prevalence in Europe in the last two decades has tripled and 150 million adults and 15 million children and adolescents in the region are today estimated to be obese (Berghöfer et al., 2008). After the United Kingdom, Spain is the EU country to have recorded the highest increases in its standardised rate of obesity over this period (OECD, 2012) and ranks high in terms of overweight and obesity levels on the continent. The latest data from the European Health Survey (2009) report that 38\% (16\%) of Spanish adults are overweight (obese) (cf. OECD, 2012).

The condition is a major public health concern since obesity is a key risk factor for a range of chronic illnesses (including, hypertension, diabetes, cholesterol, heart disease, stroke, gallbladder disease, biliary calculus, narcolepsy, osteoarthritis, asthma, apnoea, dyslipidaemia, gout and certain cancers) that tend to reduce the quality of life and ultimately result in death (Alberti et al., 2009; López-Suárez et al., 2008). Additionally, a significant number of obese patients tend to suffer mental disorders and social rejection leading to a loss of self-esteem, a particularly sensitive issue in the case of children (Gariepy et al., 2010). Given its prevalence and association with multiple chronic illnesses, obesity tends to increase healthcare resource utilisation and costs substantially.

The aim of the paper is to estimate the increase of direct medical costs of both severe $\left(\mathrm{BMI} \geq 35 \mathrm{~kg} / \mathrm{m}^{2}\right)$ and moderate $\left(30 \leq \mathrm{BMI}<35 \mathrm{~kg} / \mathrm{m}^{2}\right)$ obesity and also overweight $(25 \leq$ BMI $<30 \mathrm{~kg} / \mathrm{m}^{2}$ ) with respect to a normal-weight individual, using a two-part generalised linear model and a longitudinal dataset based on medical and administrative records of patients in primary and secondary healthcare centres followed up over seven consecutive years (2004-2010) in Spain. The effect of BMI and two additional methodological frameworks are also examined for robustness purposes. Since medical costs and obesity/ overweight may have an endogenous relationship an IV estimation is additionally performed based on children's information. This is, as far as we know, the first application exploring the impact of body weight on healthcare costs using longitudinal information containing objective health, weight and height (and consequently the BMI) measurements. Then, we report findings for the association between body weight and healthcare costs in a European country whose healthcare centres operate under a typical NHS and strict cost-containment policies were implemented during the period of analysis. 
Our results indicate that severe and moderate obesity imposes a substantial burden on the Spanish health care system. Specifically, being severely obese is associated with increases in medical costs of $26 \%$ (IV estimate: $34 \%$ ) compared to a normal-weight individual. The effects of moderate obesity and overweight are more modest raising medical costs by $16 \%$ (IV estimate: 29\%) and 8.5\% (IV estimate: 23\%), respectively. These changes in costs are slightly higher for those patients below the median age and for the women. Notwithstanding, the effects found in this study are comparatively much lower than that reported for the US, based basically on a private healthcare system and characterised by a more obese population.

The paper is organised as follows: Section 2 presents the related literature; Section 3 describes the empirical strategy; Section 4 describes the data; Section 5 presents the results, Section 6 discusses the main policy implications of the findings and Section 7 concludes.

\section{Related Literature}

A sizeable body of literature quantifies the magnitude of healthcare expenditure associated with the obesity condition. Barrett et al. (2008) distinguish two different lines of research on the subject. Thus, one set of studies concerns itself with the estimation of annual direct costs of obesity at an aggregate level. Most of them follow an "etiologic fraction" approach and consider the most frequent obesity-related diseases (Wolf and Colditz, 1998; Colditz, 1999; Sander and Bergemann, 2003; Vazquez-Sanchez and Alemany, 2002; MüllerRiemenschneider et al., 2008), while others make estimates relying on representative sample data (Finkelstein et al., 2004; Arterburn et al., 2005). These studies report that the proportion of national health care expenditure attributable to obesity ranges from 5.3 to $7 \%$ for the US and from 0.7 to $2.6 \%$ in other countries. In Spain, the share is reported to reach $7 \%$ of total health care expenditure. ${ }^{1}$ A second set of studies takes a lifetime perspective and employs medical records in order to estimate the impact of BMI categories on resource utilisation and direct costs. Most are based on US data (Quesenberry et al., 1998; Thompson et al., 2001; Raebel et al., 2004; Finkelstein et al., 2005; Wee et al., 2005) and very few on data from other countries (Borg et al., 2005; Nakamura et al., 2007; van Baal et al., 2008).

The study we report here is conducted in line with this second set of studies. But while we employ microdata and take a longitudinal perspective, the methods adopted differ significantly. We specifically apply panel data methods which have been widely recognised in

\footnotetext{
${ }^{1}$ Among studies of this type, a number estimate medical costs and obesity based on survey data (Sturm, 2002; Andreyeva et al., 2004; Von Lengerke et al., 2006).
} 
the literature on the estimation and prediction of healthcare expenditure using cross-section data. Namely, our paper is methodologically similar to those of Cawley and Meyerhoefer (2012) and Wolfenstetter (2012), although their estimations of the medical costs of obesity and overweight rely on cross-section data. ${ }^{2}$

\section{Empirical Methods}

\subsection{The Two-Part Model}

We model the increase in medical costs associated to obesity and overweight using a "twopart model" (2PM). This strategy has been widely used for analysing outcomes with a large proportion of zero observations (non-users), a strongly skewed distribution as well as a long right-hand tail of individuals who make a heavy use of healthcare resources (Manning et al., 1981; Duan et al., 1983; Duan et al., 1984). ${ }^{3}$

Specifically, the first part of the $2 \mathrm{PM}$ is estimated using a random effects (RE) logit binary regression model and the second part is specified as a Generalised Linear Model (GLM) panel regression of (positive) direct medical costs on a set of controls. ${ }^{4}$ GLM has become a dominant strategy to modelling healthcare costs when there are unknown forms of heteroskedasticity (Mullahy, 1998; Manning and Mullahy, 2001; Buntin and Zaslavsky 2004; Manning et al. 2005, Manning, 2006). ${ }^{5}$ Since GLM estimates are performed on the raw medical cost scale, there is no need for retransformation. In addition this approach allows for heteroskedasticity through the choice of the distribution function. We calculated Pregibon's link test and the Park (1966) test to determine which specific link and distribution functions best fits the data, respectively. However, the most frequently used GLM specifications in healthcare cost studies are the log link function and the Gamma distribution (Manning and Mullahy, 2001; Manning et al., 2005). Note that although GLM is recommended, Manning and Mullahy (2001) point out that GLM estimation suffers a substantial loss in precision in the face of heavy-tailed, log scale residuals or when the variance function is misspecified

\footnotetext{
${ }^{2}$ This is the first paper to estimate the (causal) impact of obesity on medical costs using the MEPS 2000-2005 data and applying the aforementioned methods in health econometrics.

${ }^{3}$ In our dataset medical costs are zero for $16 \%$ of the sample and positive medical costs are highly skewed to the right.

${ }^{4}$ Both equations of the 2PM are estimated by RE (the errors are normal distributed and uncorrelated with the regressors) due to the unfeasibility of estimating GLM models by fixed effects.

${ }^{5}$ We have certainly detected the presence of heteroskedasticity in our dataset by means of the Breusch-Pagan and White tests, produced by several covariates, some of which are continuous (i.e., complex heteroskedasticity).
} 
(Buntin and Zaslavsky, 2004; Baser, 2007). ${ }^{6}$ Notice that when we compute the incremental effect (IE) of obesity and overweight or the marginal effect (ME) of the BMI regressor on medical costs we take into account that this is not as straightforward as it is in linear regression models (Hertz, 2010).

\subsection{Alternative Empirical Models}

Two alternative models are however examined as a robustness exercise. On the one hand we estimate a single equation FE linear regression model on the logarithm of medical costs, reducing the degree of skewness and kurtosis and making the distribution more symmetric and closer to normality. ${ }^{7}$ Notice that under this approach zero cost observations are left apart if one considers that this problem is not too significant. ${ }^{8}$ Here the computation of the IE (ME) of obesity and overweight (BMI) on costs takes into account the heteroskedasticity-adjusted retransformation procedure suggested by Mullahy (1998). On the other hand, we estimate a sample selection model (SSM) once we assume that the independence hypothesis imposed by a 2PM (i.e., the error terms of the two parts are independent of each other) may be a strong assumption under a longitudinal context (Cameron and Trivedi, 2005; Albouy et al, 2010). Even including an extensive set of controls it is conceivable that those with positive expenditure levels may not be randomly drawn from the population (i.e., selection may depend on unobserved effects) and the results of the second stage regression suffer from bias. As a result, we estimate direct medical costs by means of a panel data SSM, using the selection correction procedure proposed by Wooldridge (2010). ${ }^{9}$

\subsection{Some Econometric Challenges}

\footnotetext{
${ }^{6}$ A finding that emerges from the literature that compares the performance of several models for positive expenditures in terms of consistency and precision (Manning and Mullahy, 2001; Buntin and Zaslavsky, 2004; Manning et al., 2005; Baser, 2007; Hill and Miller, 2010) is that no one method dominates the other and there are important trade-offs in terms of precision and bias, mainly when different subgroups of population or types of medical costs are analysed (Hill and Miller, 2010; Jones, 2010). Notwithstanding, Mihaylova et al. (2011) literature review confirms that 2PM models perform better.

${ }^{7}$ Estimates based on logged models are actually often much more precise and robust than direct analyses of the unlogged original dependent variable (Manning, 1998). They may also reduce (but not eliminate) heteroskedasticity.

${ }^{8}$ This is not our particular view and for this reason our central analytical framework is a 2PM.

${ }^{9}$ Wooldridge (2010) proposed to run a robust probit estimation of not having positive costs for each period $t$ and then save the inverse Mill's ratios. These were later added to the second equation estimated using a RE GLM model. We bootstrapped these procedures. Statistical significance of almost all these Mill's ratios denoted the presence of sample selection bias. Likewise, given that the Mills ratio is not strictly exogenous and causes a problem of multicollinearity, we introduced exclusion restrictions to greatly reduce these inconveniences.
} 
Some econometric challenges posed by our panel data were considered in the estimations. First, a patient's weight and height are not always measured when visiting the doctor, which means that for a subset of individuals their BMI may present a missing value in time $t$. To deal with this problem, we restricted the sample to those individuals who had at least one weight and height measurement. Based on this information we were able to infer the individuals' BMI for the period 2004-2010. ${ }^{10}$ Second, since not having weight and height measurement information may induce sample selection bias, we followed Wooldridge's (2005) proposal to accommodate this impact. In other words, we ran a robust probit estimation of not having covariate measurements for each period $t$ and then saved the inverse Mill's ratios. These were later added to the regression equations.

Third, under RE estimation we allow for the possibility that the observed BMI (when this is the regressor of interest) may be correlated with the time-invariant and individualspecific effect $\left(\alpha_{\mathrm{i}}\right) .{ }^{11}$ However, here we followed the Mundlak (1978) procedure which uses within-individual means of the BMI rather than separate values for each year. As a consequence, the original set of regressors is augmented with the global BMI mean. Fourth, to further control for heterogeneity we considered the impact of the previous year's obesity categories (or BMI) on our regressions. Notice that although some endogenous effects may still be present (a health status shock via an accident or a job loss) with a marked impact on medical spending we assumed that no other effects at the individual level could be controlled for.

Fifth, we also examined a dynamic panel regression specification by including the medical costs incurred in the previous year as an additional regressor to capture state dependence. To deal with the initial conditions problem, we followed Albouy et al. (2010) proposal which modifies Wooldridge's (2005) approach. In fact, these authors proposed using the generalised residual of a simple model in cross-section at the initial date but taking into account the two-part model framework. The latter can be considered the best available estimation of the over or under propensity to consume health resources at the initial date. Sixth, a further sample selection issue of concern occurs if during the analysed period individuals drop out from the panel because of immigration, incapacity, death, etc. We found that around $3 \%$ of our total observations suffered attrition as a consequence of death. Here,

\footnotetext{
${ }^{10}$ A definition of BMI including patients with three or more measurements was also examined, highlighting a potential trade-off between accuracy of BMI definition and sample selection issues.

11 In line with Chamberlain (1980), one option could be to assume that $\alpha_{i}=\alpha^{\prime} B M I_{i}+u_{i}: i d d N\left(0, \sigma^{2}\right)$ where $\mathrm{BMI}_{\mathrm{i}}=\left(\mathrm{BMI}_{\mathrm{i} 1}, \ldots, \mathrm{BMI}_{\mathrm{iT}}\right)$ are the values of the BMI for every year of the panel, and $\alpha=\left(\alpha_{1}, \ldots \ldots, \alpha_{\mathrm{T}}\right)$.
} 
the strategy adopted involved simply including a dummy on the occurrence of death rather than including an additional probability of individuals' dropping out from the panel. Finally, the IE and ME were computed manually as a consequence of having transformed data and were conveniently bootstrapped.

\section{Data and variables}

Panel and individual level data of the type required by the empirical analysis followed in this paper is simply not available for the whole Spain. As an alternative, we use observational and longitudinal data drawn from administrative and medical records of patients followed up over seven consecutive years in six primary care centres (Apenins-Montigalà, Morera-Pomar, Montgat-Tiana, Nova Lloreda, Progrés-Raval and Marti i Julià) and two reference hospitals (Hospital Municipal de Badalona and Hospital Universitari Germans Trias i Pujol), in the north-eastern sector of Barcelona serving more than 104,000 inhabitants. This sample of users is mostly urban, of lower-middle socioeconomic status from a predominantly industrial area. Our sample includes patients aged 16+ who had at least one contact with the healthcare system between 1 January 2004 and 31 December 2010, and who were assigned to one of the aforementioned healthcare centres during this period. ${ }^{12}$ The study also considers those who died during the period analysed. However, we exclude subjects that were transferred or who moved to other centres and patients from other areas or regions. ${ }^{13}$

The information used is gathered from a small but representative set of health care centres from a country (Spain) organised under a fully funded and decentralised (at the regional level) NHS system predominantly within the public sector. Provision is free of charge at the point of delivery with the exception of pharmaceuticals entailing some copayments.

This dataset incorporates a rich set of information about the individual patients' use of healthcare resources (including, number of visits to the GP; specialist and emergency care; number of hospitalizations and bed days; laboratory, radiology and other diagnostic tests; and consumption of medicines), their clinical measurements of height and weight, and each patient's chronic conditions and other diagnosed diseases (according to the ICPC-2), any

\footnotetext{
12 The sample contains observations with zero medical costs because there are individuals who contacted -at some point during the analysed period- the health system and incurred in positives costs, but in other years have zero costs.

${ }^{13}$ Although we have a sample of users, they are almost the entire population representing $96.52 \%$ of total residents in the specific considered geographic area. The NHS nature of the Spanish health care system may explain why we observe this high percentage during a consecutive period of seven years.
} 
functional limitations, their date of admission and discharge, type of healthcare professional(s) contacted and the motive of their visit. Moreover, the dataset includes details of each patient's age, gender, employment status (active/retired), place of birth and habitual residence.

Owing to a unique identifier, the data from the administrative and medical records can be merged with the Population Census allowing us to incorporate new variables for each patient (e.g., education or marital status) not available in the original sample.

\subsection{Data on Healthcare Costs}

In addition to its longitudinal nature, the dataset provides a wide array of information on healthcare costs. This includes the specific characteristics of the primary and hospital healthcare centres considered and also the extent of development of their information systems. In addition to these internal sources, costs were also calculated (where necessary) using data taken from invoices for intermediate products issued by a number of different providers and from the prices fixed by the Catalan Health Service.

The computation of healthcare costs follows a two-stage procedure: first, incurred expenditures (financial accounting) are converted into costs (analytical accounting), which are then allocated and classified accordingly. ${ }^{14}$ Depending on the volume of activity, we consider two types of costs: fixed or semi-fixed costs and variable costs. The former include personnel (wages and salaries, indemnifications and social security contributions paid by the health centre), consumption of goods (intermediate products, health material and instruments), expenditures related to external services (cleaning and laundry), structure (building repair and conservation, clothes, and office material) and management of healthcare centres, according to the Spanish General Accounting Plan for Healthcare Centres. The latter include costs related to diagnostic and therapeutic tests and pharmaceutical consumption. ${ }^{15}$

Our unit of measurement is the cost per treated patient during the period in which the subject was observed and all the direct cost concepts imputed for the set of diagnosed episodes. Table 1 presents our estimates of the resulting unitary cost rates for the years 2004 and 2010. As such, the total medical costs per patient in each period are calculated as the sum

\footnotetext{
14 Expenditures not directly related to care (e.g. financial spending, losses due to fixed assets, etc.) were excluded from the analysis.

${ }^{15}$ For instance we considered: (i) laboratory tests (haematology, biochemistry, serology and microbiology), (ii) conventional radiology (plain film requests, contrast radiology, ultrasound scans, mammograms and radiographs), (iii) complementary tests (endoscopy, electromyography, spirometry, CT, densitometry, perimetry, stress testing, echocardiography, etc.); iv) pharmaceutical prescriptions (acute, chronic or on demand).
} 
of fixed and semi-fixed costs (i.e., average cost per medical visit multiplied by the number of medical visits) and variable costs (i.e., average cost per test requested multiplied by the number of tests + retail price per package at the time of prescription multiplied by the number of prescriptions). Note that in this study we do not account for the computation of 'out-ofpocket payments' paid by the patient or family, as they are not registered in the database. Healthcare costs figures were converted to 2010 Euros using the Consumer Price Index (CPI).

[Insert Table 1 around here]

\subsection{Other variables}

The body mass index (BMI) of each patient was calculated as weight (in kilograms) divided by the square of height (in metres) using clinical or measured information. Notice that in our sample not all patients were measured when they visited the physician; however, others were measured on more than one occasion. We tried to account for this specific problem as previously mentioned. Obesity and overweight conditions were calculated by using the following WHO classification that distinguishes between normal-weight $(18 \leq \mathrm{BMI}<25$ $\left.\mathrm{kg} / \mathrm{m}^{2}\right)$, overweight $\left(25 \leq \mathrm{BMI}<30 \mathrm{~kg} / \mathrm{m}^{2}\right)$, moderate (class I) obesity $\left(30 \leq \mathrm{BMI}<35 \mathrm{~kg} / \mathrm{m}^{2}\right)$ and severe (class II) obesity (BMI of $\geq 35 \mathrm{~kg} / \mathrm{m}^{2}$ ). The obesity category was subdivided since the costs of excess weight come mainly from heavier individuals. ${ }^{16}$ The influence of the continuous BMI regressor on medical costs was also examined.

To identify the impact of obesity and overweight (or, alternatively BMI) on medical costs we included a wide range of covariates. First, we controlled by the patients' demographic characteristics, including age and gender, and also by immigrant status, since there is evidence that the immigrant population presents a different pattern of use and access to healthcare services. Note that non-linear age effects were considered after running the modified Hosmer-Lemeshow test. We also added a set of dummies to control for their employment status (active/retired), lifestyles (smoking and alcohol consumption), whether the individual was the main beneficiary of the public health insurance, and whether Catalan was their usual language of communication. Importantly, since under a clinical point of view it can be very difficult to isolate non-obesity related medical conditions, our econometric

\footnotetext{
${ }^{16}$ Although the BMI is the most widely used measure of obesity, it is not free of problems. For instance, the BMI does not take into consideration body composition (adiposity vs. lean weight) or body fat distribution. This means it may fail to predict obesity among very muscular individuals and the elderly.
} 
specifications will not control for any specific disease. However, as a robustness check we will examine how results are changed when some conditions unconnected (in principle) with obesity and overweight are controlled for. Merging these data with the Population Census allowed us to control medical costs by the patients' educational level and marital status.

We have an initial unbalanced panel dataset containing 706,473 observations for the whole period 2004-2010. However, when we restrict the sample to patients presenting at least one weight and height measurement, the final sample is reduced to 452,108 observations $(64 \%){ }^{17}$

\section{Results}

\subsection{Summary Statistics}

Descriptive statistics for the main set of variables used in the empirical exercise are presented in Tables 2-4. Table 2 shows that the mean annual total medical costs per patient for the period 2004-2010 is $755.11 €$ (in 2010 Euros), which is considerably higher than the median of $306.92 €$ (less than half that of the mean cost in our final sample). The skewness statistic (5.91 compared to 0 for symmetric data) and the kurtosis coefficient (82.97 compared to 3 for normal data) indicate that the distribution of costs in levels is highly skewed to the right. As expected, the logarithmic transformation reduces the range of variation of costs, narrowing the degree of skewness: the mean medical cost (6.01€) approximates to that of the median (6.09€) and the skewness (kurtosis) statistic falls to -0.23 (2.66). Although not shown, mean (median) annual medical costs in the initial sample amounts to $544.04 €(139.93 €){ }^{18}$

[Table 2 around here]

Direct medical costs are zero for $16.4 \%$ of the sample $(74,144$ obs.) while the number of observations with positive medical costs is 377,964 . As Table 3 shows, mean positive annual costs per patient reaches $903.09 €$. This figure is significantly higher for women $(949.40 €)$

\footnotetext{
${ }^{17}$ Of course, a much more reduced sample is obtained (around 80,000 observations) when individuals with 3 or more anthropometric measurements are considered.

${ }^{18}$ Interestingly, a roughly $40 \%$ of the observations without BMI measurements are immigrants. This particularity may help to explain why they are less measured. As they are younger, have less medical episodes and less severity, medical expenditures in the final sample are relatively larger.
} 
than it is for men (845.96€). As expected, medical costs increase with patients' age, with a higher Charlson comorbidity index and with terminal illness.

[Table 3 around here]

Finally, Table 4 summarises the mean and standard deviation values of the variables of interest and of the controls. In our sample, the mean BMI in the period of study is 26.70 , corresponding to a prevalence of moderate (class I) obesity (overweight) of $23 \%$ (36\%). As expected, the mean measured BMI is slightly higher among men (26.75) than it is among women (26.67), with the prevalence of class I obesity being higher among women (25\% vs. $21 \%$ ) and overweight among men (42\% vs. $31 \%$ ). Severe (class II) obesity is also much more prevalent among women $(8.7 \%)$ than among men $(4.4 \%)$ in our dataset. This differential pattern of prevalence rates by gender is also observed for the US, although at a lower level. Notice that women represent $54 \%$ of the sample and that they are slightly older than men (48.86 vs. 47.52 years of age). Note that as we are using a sample of users aged $16+$, this average age (48) is higher than the average age for the entire Spanish population (41 in 2011), which means that we are using a skewed sample of users towards older ages. Notwithstanding, if we included the non-adult group of users our sample average age is 42.9 . Differences by gender are also found with respect to smoking (28\% $\mathrm{M}$ vs. $17 \% \mathrm{~W})$ and alcohol (3.5\% vs. $0.4 \%$ ) behaviours and public health insurance (95\% vs. $82 \%$ ), closely related to the higher participation of men in the labour market. As for labour status, around $67 \%$ of the sample is active and the percentage of individuals who have to be dropped from the sample due to death is higher among men (3\% vs. $2 \%)$.

[Table 4 around here]

\subsection{Obesity, Overweight and Direct Medical Costs}

In Tables 5-8 we present the results of our panel data estimations. Specifically, these tables show the bootstrapped estimates of the incremental effects (IEs) of the patients' measured obesity types and overweight on total medical costs. Alternatively, the bootstrapped marginal effects (MEs) are calculated when BMI is the regressor of interest. Accompanying these estimates, we also report measures of goodness of fit and of the predictive performance for each model (i.e., the auxiliary $\mathrm{R}^{2}$, the root mean square error - RMSE, and the mean absolute 
prediction error - MAPE). Note that these estimations account for a wide list of controls (see Section 4.2), health district dummies and time dummy variables. In addition, as discussed previously, each model incorporates the inverse Mill's ratio of not having weight and height measurements, the global mean BMI or the Mundlak correction procedure (when needed), one-year lagged class I and II obesity and overweight rates (or measured BMI) and a dummy for the occurrence of death. The number of bootstrap replications is set at 200.

The first set of results in Table 5 presents the IEs or the increase in annual direct medical costs of severe obesity, moderate obesity and overweight using a 2PM approach. Notice that the first part of the 2PM specifies a panel data probit model to estimate positive medical costs while the second part uses GLM panel data regression based on a Gamma distribution with the $\log$ link function (widely used in the literature on health care costs). ${ }^{19}$ Two econometric specifications are examined. According to the first specification (section 5.A) and the static version, we find a positive and statistically significant (at 1\%) moderate obesity and overweight impacts on medical costs. Namely, compared with normal-weight individuals becoming moderately obese raises direct medical costs by $109.30 €$ per patient and year. As expected the impact of the overweight status on such costs is notably lower (46.85€). Under the dynamic version (where we include a one period lag dependent variable in both equations of the 2PM) the IEs of both moderate obesity and overweight on costs is slightly stronger (115.37€ and 56.04€, respectively). Interestingly, a relatively better performance is achieved using the latter model compared to the non-dynamic version.

\section{[Table 5 around here]}

According to the second specification (section 5.B) where the obesity category is further subdivided and the dynamic version is used, we find, as expected, a much stronger impact of severe obesity on medical costs compared to moderate obesity. Certainly, severely (moderately) obese individuals raise medical costs by an amount of $161.85 €(99.81 €)$ per patient and year; whereas overweight raises medical costs by roughly $52 €$ per patient annually. In other terms, with total medical costs averaging $600 €$ for normal-weight individuals, the estimated extra annual costs of severe obesity correspond to a $27 \%$ increase, for moderate obesity to a $17 \%$ increase, and for overweight to a $9 \%$ increase.

\footnotetext{
19 The Pregibon link test gives an estimated value of $-0.591 * 10^{-5}$ (p-value $=0.000$ ) which is practically 0 , suggesting the logarithm as the link function. The Park (1966) test gives a coefficient $v=1.79$ (p-value=0.000) which is consistent with a Gamma-class distribution.
} 
Although not shown, the GLM model performs much better than the OLS log costs estimation using a $2 \mathrm{PM}$ as long as the RMSE and MAPE (auxiliary $\mathrm{R}^{2}$ ) measures decrease (increase) substantially. ${ }^{20}$

\subsection{Impact of Obesity by Groups}

To assess how the above estimations vary with respect to different sample groups, Table 6 presents the IEs of the two obesity classes and overweight differentiating by gender and age, given the evidence of a marked differentiated pattern in the utilization of healthcare resources by these two populations in most western countries. The reference approach is again the 2PM GLM model with the dynamic version given its superior comparative fit. This set of new estimates includes the same controls as those accounted for in the previous tables. Interestingly, we find that the increase in medical costs per patient and year associated with these conditions is more powerful among women (W) than among men (M). Specifically, severe obesity raises medical costs by $170.07 €(\mathrm{~W})$ vs. $145.64 €(\mathrm{M})$; moderate obesity raises costs by $115.83 €(\mathrm{~W})$ vs. $84.61 €(\mathrm{M})$ and overweight raise costs by $60.73 €(\mathrm{~W})$ vs. $43.49 €$ (M). In terms of relative changes, once the average costs of normal-weight individuals for both men and women are taken into account, severely (moderately) obese women raise medical costs by $29 \%$ (19.5\%); whereas severely (moderate) obese men increase costs by just $24 \%(14 \%)$.

A similar picture emerges when the sample is split by age. Severe obesity has a larger effect on medical costs in absolute terms among those aged above the median age of 42 (209.90€) than those aged below (87.34€). However, the relative rise was slightly higher among the younger subgroup ( $25 \%$ vs. $21.5 \%$ ). The same is true for moderate obesity and overweight.

[Table 6 around here]

\subsection{A Robustness Analysis}

\footnotetext{
${ }^{20}$ These results can be provided by the authors upon request.
} 
Table 7 is devoted to present some robustness analysis. Instead of assessing the impact of BMI categories, Section 7.A shows the estimated effect of measured BMI on healthcare costs. We report the bootstrapped marginal effect (ME) of BMI on direct medical costs using a 2PM with a GLM procedure for the second part based on a Gamma distribution and the log link function. Notice that we included here the Mundlak correction procedure and the one-year lagged BMI regressor, when the rest of the econometric issues posed by the data set were accounted for. As expected, our results show a highly significant and positive estimated ME of BMI on medical costs. Under the "static" version we find that one additional unit of BMI (or $2.7 \mathrm{~kg}$. weight increase) results in an increase of $11.62 €$ in average total medical costs per patient and year. Under the dynamic version, a slightly lower marginal influence on mean annual costs is found (10.40€) when the individual's BMI rises in one unit. Again, the accuracy and goodness of fit achieved with this latter estimation is greater, in terms of lower RMSE and MAPE and higher auxiliary $\mathrm{R}^{2}$.

\section{[Table 7 around here]}

In order to check the sensitivity of the above results based on the 2PM framework, two alternative methodological approaches are examined (section 7.B). This analysis is performed using individual BMI as the variable of interest, which allows us to compare estimations easily. The first row shows the impact of BMI via the estimation of a single equation FE linear regression model of the logarithm of medical costs, using the sample of patients who incurred in positive costs. Clearly, this strategy leaves apart the zero observations problem. However, a heteroskedasticity-adjusted retransformation procedure was applied in the estimation of the ME of BMI. This need was evidenced by the following tests. On the one hand, the Shapiro-Wilk test rejected the null hypothesis that the log residuals were normally distributed $(\mathrm{W}=18.13$, $\mathrm{p}$-value=0.000). On the other hand, evidence of heteroskedasticity was found when regressing the squared residuals of $\log$ costs on a set of covariates (Chisquared $=1.18 * 10^{6}, \mathrm{p}$-value $=0.000$ ). A variant of the Park test suggested that several covariates contributed to this heteroskedasticity. Therefore, according to the dynamic version of this model, we find that one additional unit of BMI (or $2.7 \mathrm{~kg}$. weight increase) results in a raise of $6.73 €$ in annual total medical costs per patient, which is clearly lower than the impact computed through the $2 \mathrm{PM}$ framework $(10.40 €)$. Notice this alternative model is much poorer 
in terms of goodness of fit and predictive capacity. ${ }^{21}$ This finding is compatible with Hill and Miller (2010) that sustain that OLS of log (costs) models tend to perform poorly in terms of their bias and predictive accuracy, making the GLM more attractive for the second part of the two-part model. Cawley and Meyerhoefer (2012) follow the same strategy when estimating their models.

The second row of section 7.B presents the estimation of direct medical costs using a panel data sample selection approach (SSM), following the selection correction procedure suggested by Wooldridge (2010). As previously mentioned, the set of IMRs obtained from a robust probit estimation of not having positive costs for each period $t$ are added in the estimation of a RE GLM model (with log link and Gamma distribution). The exclusion restrictions are labour status, public insurance coverage and immigrant status. The dynamic version of this SSM shows again a positive and significant ME of BMI on medical costs (11.20€) which is roughly similar to the effect computed using the $2 \mathrm{PM}$ approach. ${ }^{22}$ However, in our data the IMRs are statistically significant at $10 \%$ just in 2 out of the 7 years analysed. Additionally, we follow the test of independence of the two error terms suggested by Albouy et al. (2010) and we cannot reject the null assumption. On the basis of these findings, the central estimates of the impact on medical costs will be based in this paper on the 2PM framework.

Finally, the last part of Table 7 (section 7.C) analyse, under a 2PM approach, how sensitive the impact of BMI is when certain patients' conditions are included and another sample is used. Specifically, in the first row we estimate the ME of BMI when some nonrelated-obesity conditions (e.g., asthma, COPD, psychosis, dementia, cancer) are added as controls in the specification. Interestingly, the dynamic version predicts a significant but notably lower ME of BMI on medical costs compared to our central model estimate of Table 6 (4.71€ vs. $10.40 €)$. We interpret this evidence as indicating that part of the variation in medical costs, previously attributed to the individuals' body mass, is now captured by such health conditions. However this finding would suggest that there are not really unrelated (chronic) obesity conditions and in some way or another they are connected, indirectly supporting the decision to exclude all of them to gather the real impact of obesity (BMI) on medical costs. The last row in section 7.C assesses the increase in medical costs when we

\footnotetext{
${ }^{21}$ Although not shown, an even worst fit is obtained when we apply the same method on raw (unlogged) medical costs.

${ }^{22}$ If we instead specify a log cost model for the second part of the sample selection model -following Albouy et al, 2010- and apply FE estimation we obtain a slightly lower significant ME coefficient. Note that this alternative model shows a greater RMSE value.
} 
adopt a stricter definition of BMI, i.e., including patients with three or more measurements. Interestingly, we find that this measurement of BMI increases medical costs (10.22€) in a similar magnitude that the one adopted in section 7.A when BMI is defined considering at least one weight and height measurement. Therefore, it seems that the estimation is not affected by the trade-off between accuracy of the BMI measure (given the presence of missing values) and the sample selection problem.

\subsection{IV estimation by means of biological information}

One could argue that medical costs and severe/moderate obesity or overweight may have an endogenous relationship. This is the case if patients who incur in higher utilization of healthcare resources and costs also experience a change in their bodyweight caused, for instance, by psychological factors or other diseases (e.g., cancer, dementia, and other cachexia-inducing ailments). To overcome this problem and derive a causal effect on medical costs, we followed Davey Smith et al. (2009) and Cawley and Meyerhoefer (2012) proposal and instrumented the individuals' severe obesity, moderate obesity and overweight rates with the prevalence rates of a biological relative (i.e., children's information). ${ }^{23}$ The validity of this instrument is firstly based on the fact than children and parent's obesity (BMI) are closely related not only on genetic grounds but, more importantly, as a consequence of a proven intertemporal transmission of values and lifestyles. Secondly, we assume that the instrument is uncorrelated with the error term of the equation of medical costs and with confounding factors. Contrary to Cawley and Meyerhoefer (2012) our weight and height data are clinically measured and, as such, the BMI does not suffer any misreporting and use longitudinal information to control for unobserved heterogeneity. Moreover, as long as various primary care programs (i.e., the Healthy Child Program) specifically targeted children, we have considerably more information on children's BMI to construct the instrument than was the case in Cawley and Meyerhoefer's (2012) study. We considered non-linearities in the instrument (quadratic and cubic terms).

Table 8 reports the IV estimates of the incremental effects (IEs) on medical costs assuming a 2PM-GLM dynamic version model. For comparative purposes the first row shows the non-IV IEs of the two obesity classes and overweight using the same sample size as that used under the IV estimation, which of course is greatly reduced as only individuals with

\footnotetext{
${ }^{23}$ Given that we linked our dataset to census information we were able to obtain household and parental
} identifiers. 
children are considered. Our findings indicate that the IV estimates of the causal influence of the BMI categories on direct costs are larger than those without instrumenting. Once we purge by the reverse causality problem we end up with a more powerful influence on medical costs. In particular, the results show that patients with severe obesity cause an increase in direct medical costs of $206.48 €$ ( $34 \%$ increase) per patient and year, with moderate obesity by $174.69 €\left(29 \%\right.$ increase) and with overweight by $136.02 €\left(23 \%\right.$ increase). ${ }^{24}$

\section{[Table 8 around here]}

Notwithstanding, these IV estimations should be taken with some caution as we may have a rather weak instrument. Notice that the use of family's characteristics as instruments may be problematic, for example, as individuals may decide to seek more medical care (medical treatments and diagnostic tests) when they hear about family members' illnesses, especially if these illnesses have a genetic component. Even if they don't have a genetic component, people may become more aware of different types of illnesses when their family members get ill.

\section{Conclusion}

This study has examined the association (and causal impact) of obesity and overweight with the increase of direct medical costs using a two-part model as a central approach and a longitudinal dataset of administrative and medical records of patients followed up over seven consecutive years (2004-2010) in Spain. This is the first application in the literature of this methodology based on longitudinal information and BMI measurements as opposed to selfreported data.

Obesity is related with an important number of chronic (for the rest of life) diseases affecting the health status and quality of life of patients. One clear consequence of obesity is the higher health care costs borne by the entire society (i.e., negative externality) through higher insurance premiums or taxes to cover the extra funding. Hence, understanding the link between body mass or obesity and medical costs should be then crucial to achieve a more sustainable growth of health expending; especially at a time of increased pressure to cut successively public budgets. It should also serve as a way to stimulate the allocation of more resources into prevention actions to tackle the development of the epidemic.

\footnotetext{
${ }^{24}$ Note that these results provide an estimate of the Local Average Treatment Effect (LATE) of being obese or overweight on medical costs for a sample of individuals with children.
} 
The results indicate that obesity is associated with substantial healthcare costs increases and there are large differences in costs by degree of obesity. Specifically, severe obesity raises total direct medical costs by an average of $160 €$ per patient and year. With total medical costs averaging $600 €$ for normal-weight individuals, this means that severe obesity is associated with an increase in costs of $26 \%$. The effect of moderate obesity is more modest: it raises medical costs by $97 €$ or $16 \%$ increase. Overweight has an even smaller impact raising costs by $51 €$ or $8.5 \%$ increase. This evidence shows that the burden imposed on the health care system by these conditions grows large for the most obese segment of the Spanish population.

The relative changes in medical costs are slightly higher for those patients below the median age and for the women. Severe (moderate) obesity raises medical costs around 29\% $(19.5 \%)$ in case of women and just $24 \%(14 \%)$ in case of men. Alternatively, severe (moderate) obesity increase costs by $21 \%$ (12\%) for those aged above the median age of 42 but $25 \%$ (18\%) for those younger than this threshold. This latter finding would be compatible with other results indicating a weak association between high BMI levels and adverse health outcomes among old-age individuals.

Our IV estimations predict an even higher (causal) effect of the BMI categories on direct costs. Based on the full sample, the results show that patients with severe obesity increase medical costs by $206 €$ (34\% increase) per patient and year; moderate obesity by $175 €$ (29\% increase) and overweight by $136 €$ (23\% increase).

To put these estimates in perspective, the costs increases documented in this paper compare well with the findings provided, for instance, by Sturm et al. (2013). These authors using cross-sectional data of a comprehensive medical scheme in South Africa find that severe (moderate) obesity increases annual medical expenditures by $23 \%(11 \%)$ in the year 2010. However, the estimated impacts on costs are certainly lower than those calculated for the US. Finkelstein et al. (2004) combining the MEPS and NHIS datasets for the US find that (moderate) obesity is associated with a $37 \%$ increase in annual medical spending. Similarly, Thorpe et al. (2004) combining other US data show that costs incurred by obese individuals (BMI $\geq 30$ ) were $37 \%$ higher than costs for those with normal weight in 2001 . The impacts of bodyweight on mean healthcare costs shown by Cawley and Meyerhoefer (2012) for the US or von Lengerke et al. (2010) for Germany are also larger than the effects we find for Spain.

Again, our estimates are also much more modest when the analysis is restricted to individuals aged 54-69 to parallel some US studies (Andreyeva et al., 2004; Sturm et al., 2013). According to our regressions we find that severe (moderate) obesity is associated with 
increases in medical costs of $24.5 \%$ (14\%) for this age group. This is substantially lower to the US estimations for the same age group reported by such studies, where severe obesity was related with an increase of more than $50 \%$ and moderate obesity with an increase of $25 \%$.

A tentative explanation could be that, in addition of having lower levels of fatness, the Spanish healthcare system provides universal coverage and its services are free at the point of delivery. Furthermore, during the period of analysis, strict cost-containment policies were in operation. These results have important implications for public health policies as they suggest that reducing population levels of obesity and overweight (or preventing their rise) will have a considerable benefit not only to population health but also on government budgets. Although some argue that the onset of obesity-unrelated diseases due to the life-years gained by the prevention policies could even offset the gains in costs.

This paper has several limitations that should be noted. First, the study sample includes individuals living in an urban city of Catalonia which makes the extrapolation to the entire Spanish population difficult. Second, the sample contains individuals with no BMI measurements or observations with zero medical costs. This omission may bias the results when a significant share of the individuals with no BMI measurements are immigrants and enjoy a relatively better health status. Third, our central estimates do not include controls on medical conditions given the complex task of isolating the group of non-obesity related medical conditions of the patients. Fourth, as income is not collected in the dataset the estimations do not control for this potential confounder of the relationship between BMI classes and direct medical costs. Fifth, another limitation is the (weak) validity of the instrument based on children's information. Finally, like the previous literature this paper uses BMI as a measure of fatness given the impossibility of using more refined measurements (i.e., body fat percentage or waist circumference). 


\section{References}

Alberti, KG, Eckel RH, Grundy SM, Zimmet PZ, Cleeman JI, Donato KA, Fruchart JC, James WP, Loria CM, Smith SC Jr., 2009. Harmonizing the metabolic syndrome: a joint interim statement of the International Diabetes Federation Task Force on Epidemiology and Prevention; National Heart, Lung, and Blood Institute; American Heart Association; World Heart Federation; International Atherosclerosis Society; and International Association for the Study of Obesity. Circulation; 120: 1640-1645.

Albouy, V., Davezies, L., Debrand, T., 2010. Health expenditure models: a comparison using panel data. Econ. Model., 27, 791-803.

Andreyeva T., Sturm R., Ringel JS., 2004. Moderate and severe obesity have large differences in health care costs. Obes. Res. 12: 1936-1943.

Aranceta Bartrina J., Serra Majem Ll., Foz Sala, Moreno Esteban B., 2005. Grupo Colaborativo SEEDO. Prevalencia de la obesidad en España. Med. Clin. (Barc.) 125: 460466.

Arterburn D.E., Maciejewski M.L., Tsevat J., 2005. Impact of morbid obesity on medical expenditures in adults. International J. Obes. 29: 334-339.

Barrett AM, Colosia AD, Boye KS, Oyelowo O. Burden of obesity: 10-year review of the literature on costs in nine countries. ISPOR $13^{\text {th }}$ Annual International Meeting, May 2008, Toronto, Ontario, Canada.

Baser O., 2007. Modeling transformed health care cost with unknown heteroskedasticity. App. Econ. Res. Bull. 1: 1-6.

Berghöfer A., Pischon T., Reinhold T., Apovian C.M., Sharma A.M., Willich S.N., 2008. Obesity prevalence from a European perspective: a systematic review. BMC Public Health. 2008; 8: 200.

Borg S., Persson U., Odegaard K., Berglund G., Nilsson J.A., Nilsson P.M., 2005. Obesity, survival, and hospital costs-findings from a screening project in Sweden. Value Health: 56271.

Buntin M.B., Zaslavsky A.M., 2004. Too much ado about two-part models and transformation? Comparing methods of modelling Medicare expenditures. Journ. Health Econ., 23: 525-542.

Cameron A.C., Trivedi P.K., 2005, Microeconometrics: Methods and Applications. New York: Cambridge University Press.

Cawley J., Meyerhoefer C., 2012. The medical care costs of obesity: an instrumental variables approach. Journ. Health Econ., 31: 219-230.

Chamberlain G., 1980. Analysis of covariance with qualitative data. Rev. Econ. Stu. 47: 225238. 
Colditz G.A., 1999. Economic costs of obesity and inactivity. Med. Sci. Sports Exerc. 31 (11 Suppl): S663-S667.

Davey Smith G., Sterne J., Fraser A., Tynelius P., Lawlor D.A., Rasmussen F., 2009. The association between BMI and mortality using offspring BMI as an indicator of own BMI: large intergenerational mortality study. BMJ 2009; 309:b5043. doi:10.1136/bmj.b5043.

Duan N., 1983. Smearing estimate: a nonparametric retransformation method. J. Amer. Statist. Assoc. 78: 605-610.

Duan N., Manning, W.G., Morris C.N., Newhouse, J.P., 1983. A comparison of alternative models for the demand for medical care. J. Bus. Econ. Stat. 1(2): 115-126.

Duan N., Manning, W.G., Morris C.N., Newhouse, J.P., 1984. Choosing between the sampleselection model and the multi-part model. J. Bus. Econ. Stat. 2(3): 283-289.

Finkelstein E.A., Fiebelkorn I.C., Wang G., 2004. State level estimates of annual medical expenditures attributable to obesity. Obes. Res. 12: 18-24.

Finkelstein E.A., Fiebelkorn I.C., Wang G., 2005. The costs of obesity among full-time employees. Am. J. Health Promot. 20: 45-51.

Gariepy G., Nitka D., Schmitz N., 2010. The association between obesity and anxiety disorders in the population: a systematic review and meta-analysis. Int. J. Obes. (Lond). 34: 407-419.

Grossman M., 1972. On the concept of health capital and the demand for health. Journ Pol. Eco. 80: 223-255.

Hertz T., 2010. Heteroskedasticity-robust elasticities in logarithmic and two-part models. Appl. Econ. Lett. 17: 225-228.

Hill S., Miller G., 2010. Health expenditure estimation and function form: applications of the Generalised Gamma and Extended Estimating Equations models. Health Econ., 19: 608-627.

Jones A. M., Rice N., Bago d'Uva M.T. Balia S., 2007. Applied Health Economics, (Routledge Advanced Texts in Economics and Finance), Routledge, UK.

Jones A. M., 2010. Models for Health Care. HEDG Working Paper 10/01.

López Suárez A., Elvira González J., Beltrán Robles M., Alwakil M., Saucedo J.M., Bascuñana Quirell A., Barón Ramos M.A., Fernández Palacín F., 2008. Prevalence of obesity, diabetes, hypertension, hypercholesterolemia and metabolic syndrome in over 50-year-olds in Sanlúcar de Barrameda, Spain. Rev. Esp. Cardiol. 61: 1150-1158.

Manning, WG., Morris, CN, Newhouse, JP., 1981. A two-part model of the demand for medical care: preliminary results from the Health Insurance Study. In: van der Gaag, J., Perlman, M. (Eds.), Health, Economics, and Health Economics. North Holland, Amsterdam, pp. 103-123. 
Manning W.G., 1998. The logged dependent variable, heteroscedasticity and the retransformation problem. Journ. Health Econ. 17: 283-295.

Manning W.G., 2006. Dealing with skewed data on costs and expenditure. In Jones, AM (ed.) The Elgar Companion to Health Economics, Cheltenham: Edward Elgar.

Manning W.G., Mullahy J., 2001. Estimating log models: to transform or not to transform? Journ. Health Econ. 20: 461-494.

Manning W.G., Basu A., Mullahy J., 2005. Generalised modelling approaches to risk adjustment of skewed outcomes data. Journ. Health Econ. 24: 465-488.

Mihaylova, M., Briggs, A., O'Hagan, A., Thompson, SG., 2011. Review of statistical methods for analysing healthcare resources and costs. Health Econ., 20: 897-916. doi:10.1002/hec.1653

Mullahy, J., 1998. Much ado about two: reconsidering retransformation and the two-part model in health econometrics. Journ. Health Econ. 17: 247-281.

Müller-Riemenschneider F., Reinhold T., Berghöfer A., Willich SN., 2008, Health-economic burden of obesity in Europe. Eur J. Epidemiol. 23: 499-509.

Mundlak Y., 1978, On the pooling of time series and cross-section data. Econometrica. 46: 69-85.

Nakamura K., Okamura T., Kanda H., Hayakawa T., Okayama A., Ueshima H., 2007, Health Promotion Research Committee of the Shiga National Health Insurance Organizations. Medical costs of obese Japanese: a 10-year follow-up study of National Health Insurance in Shiga, Japan. Eur. J. Public Health. 17(5): 424-429.

OECD, 2012. Obesity updates 2012.

Park R., 1966, Estimation with heteroscedastic error terms. Econometrica 34: 888.

Quesenberry C.P Jr., Caan B., Jacobson A., 1998, Obesity, health services use and health care costs among members of a health maintenance organization. Arch. Intern. Med. 158: 466-472.

Raebel M.A., Malone D.C., Conner D.A., Xu S., Porter J.A., Lanty F.A., 2004, Health services use and health care costs of obese and non-obese individuals. Arch. Intern. Med. 164: 2135-2140.

Sander B., Bergemann R., 2003, Economic burden of obesity and its complications in Germany. Eur. J. Health Econ. 4: 248-253.

Sturm R., 2002, The effects of obesity, smoking, and drinking on medical problems and costs. Health Aff (Millwood) 21: 245-253.

Sturm R., An R., Maroba J., Patel D., 2013, The effects of obesity, smoking, and excessive alcohol intake on healthcare expenditure in a comprehensive medical scheme. S. Afr. Med. J. 103: 840-844. 
Thompson D., Brown J.B., Nichols G.A., Elmer P.J., Oster, G., 2001, Body mass index and future healthcare costs: a retrospective cohort study. Obes. Res. 9: 210-218.

van Baal P.H.M., Polder J.J., de Wit G.A., Hoogenveen R.T., Feenstra T.L. et al., 2008, Lifetime medical costs of obesity: prevention no cure for increasing health expenditure. PloS Med 5(2), e29, (DOI http://dx.doi.org/10.1371/journal.pmed.0050029).

Vázquez-Sánchez R., López Alemany J.M., 2002, Los costes de la obesidad alcanzan el 7\% del gasto sanitario. Rev. Esp. Econ. Salud, Sept-Oct 1(3).

Von Lengerke T., Reitmeier P., John J., 2006, Direct medical costs of (severe) obesity: a bottom-up assessment of over vs. normal weight adults in the KORA-study region (Augsburg, Germany). Gesundheitswesen 68: 110-115.

Von Lengerke T., John J., Mielck A., 2010. Excess direct medical costs of severe obesity by socioeconomic status in German adults. Physco. Med. 7: 1-18.

Wee C.C., Phillips R.S., Legedza A.T.R., Davis R.B., Soukup J.R., Colditz G.A., 2005. Health care expenditures associated with overweight and obesity among US adults: importance of age and race. Am. J. Public Health 95: 159-165.

Wolf A.M., Colditz G.A., 1998, Current estimates of the economics costs of obesity in the United States. Obes. Res. 6: 97-106.

Wolfenstetter, SB., 2012. Future direct and indirect costs of obesity and the influence of gaining weight: Results from the MONICA/KORA cohort studies, 1995-2005. Econ. Hum. Biol. 10: 127-138.

Wooldridge J.M., 2005, Simple solutions to the initial conditions problem in dynamic, nonlinear panel data models with unobserved heterogeneity. J. Appl. Econometrics, 20: 39-54. 
Table 1. Unit cost estimates per patient in 2004 and 2010

\begin{tabular}{|c|c|c|}
\hline Healthcare resources & $\begin{array}{c}\text { Unit costs }(€) \\
2004 \\
\end{array}$ & $\begin{array}{c}\text { Unit costs }(€) \\
2010 \\
\end{array}$ \\
\hline \multicolumn{3}{|l|}{ Medical visits: } \\
\hline Visits to Primary Medical Care & 16.09 & 24.37 \\
\hline Visits to Emergency Care & $79.49 *$ & 123.48 \\
\hline Hospitalization (per day) & $217.03^{*}$ & 337.13 \\
\hline Visits to Specialist Care & $71.30^{*}$ & 110.76 \\
\hline \multicolumn{3}{|l|}{ Complementary tests: } \\
\hline Laboratory tests & 18.33 & 22.64 \\
\hline Conventional radiology & 14.64 & 18.79 \\
\hline Diagnostic/therapeutic tests & 21.37 & 37.76 \\
\hline Pharmaceutical prescriptions & PVP & PVP \\
\hline
\end{tabular}


Table 2. Mean Annual Total Direct Medical Costs per Patient 2004-2010 (in Euros 2010)

\begin{tabular}{rcc}
\hline & \multicolumn{1}{c}{ Final Sample } \\
\hline & $\begin{array}{c}\text { Costs } \\
\text { (in Euros) }\end{array}$ & Log Costs \\
\hline Mean & 755.11 & 6.01 \\
Median & 306.92 & 6.09 \\
Standard Deviation & $1,309.96$ & 2.55 \\
& & \\
Skewness & 5.91 & -0.23 \\
Kurtosis & 82.97 & 2.66 \\
\hline $\mathrm{N}$ (Number of obs.) & 452,108 & 377,964 \\
\hline
\end{tabular}


Table 3. Mean Annual Total Direct Medical Costs per Patient 2004-2010 (in Euros 2010): Positive costs

\begin{tabular}{lccc}
\hline & \multicolumn{3}{c}{ Final Sample with Positive Costs } \\
\hline Full sample & Both Genders & Male & Female \\
& & & \\
& & & \\
& & & \\
& & & \\
Ages 16-24 subgroups: & $(1,382.42)$ & $325.67(418.85)$ & $344.10(432.24)$ \\
Ages 24-40 & $335.29(425.99)$ & $380.78(664.52)$ & $398.32(555.83)$ \\
Ages 40-54 & $390.40(607.38)$ & $574.61(855.90)$ & $664.21(847.53)$ \\
Ages 54-65 & $624.72(852.38)$ & $974.56(1,212.95)$ & $1,113.64(1,271.99)$ \\
Ages + 65 & $1,049.15(1,246.88)$ & $1,862.60(2,167.37)$ & $1,947.54(2,044.84)$ \\
Active (labour status) & $1,911.87(2,097.58)$ & $467.65(673.02)$ & $515.50(682.74)$ \\
Charlson index (>0) & $493.28(678.66)$ & $1,693.65(1,992.99)$ & $1,863.36(2,119.18)$ \\
Immigrant status & $1,777.23(2,057.78)$ & $383.81(764.77)$ & $435.35(635.88)$ \\
Deceased individuals & $411.74(698.34)$ & $3,411.68(5,066.23)$ & $3,173.23(4,292.89)$ \\
\hline N (Number of obs.) & $3,302.33(4,727.91)$ & 169,199 & 208,765 \\
\hline
\end{tabular}


Table 4. Descriptive statistics of some control variables. Period 2004-2010

\begin{tabular}{lccc}
\hline & \multicolumn{3}{c}{ Final Sample } \\
\hline & Both Genders & Male & Female \\
\hline BMI & $26.70(5.18)$ & $26.75(4.54)$ & $26.67(5.67)$ \\
Moderate Obesity & $0.23(0.42)$ & $0.21(0.41)$ & $0.25(0.43)$ \\
Severe Obesity & $0.067(0.25)$ & $0.044(0.21)$ & $0.087(0.28)$ \\
Overweight & $0.36(0.48)$ & $0.42(0.49)$ & $0.31(0.46)$ \\
\hline Age & $48.24(19.23)$ & $47.52(18.84)$ & $48.86(19.54)$ \\
Female & $0.54(0.50)$ & - & - \\
Immigrant status & $0.05(0.22)$ & $0.05(0.23)$ & $0.05(0.22)$ \\
Active (labour status) & $0.67(0.47)$ & $0.70(0.46)$ & $0.65(0.48)$ \\
Alcohol consumption & $0.019(0.14)$ & $0.035(0.18)$ & $0.004(0.21)$ \\
Smoking & $0.22(0.42)$ & $0.28(0.45)$ & $0.17(0.38)$ \\
Public health insurance & $0.88(0.32)$ & $0.95(0.21)$ & $0.82(0.38)$ \\
Catalan language & $0.99(0.09)$ & $0.99(0.10)$ & $0.99(0.08)$ \\
Deceased individuals & $0.03(0.17)$ & $0.03(0.18)$ & $0.02(0.15)$ \\
N (Number of obs.) & 452,108 & 209,637 & 242,471 \\
\hline
\end{tabular}

Note: Figures are mean values between 2004-2010. Standard deviations are reported in parentheses. Moderate obesity $\left(30 \leq \mathrm{BMI} \leq 34.9 \mathrm{~kg} / \mathrm{m}^{2}\right)$, Severe obesity $\left(\mathrm{BMI} \geq 35 \mathrm{~kg} / \mathrm{m}^{2}\right)$. 
Table 5. Increase in annual direct medical costs of severe and moderate obesity and overweight (in Euros 2010). Panel data estimation

Section 5.A

\begin{tabular}{lccccc}
\hline Two-Part Model & $\begin{array}{c}\text { IE } \\
\text { Moderate } \\
\text { Obesity }\end{array}$ & $\begin{array}{c}\text { IE } \\
\text { Overweight }\end{array}$ & RMSE & MAPE & $\begin{array}{c}\text { Auxiliary } \\
\mathbf{R}^{2}\end{array}$ \\
\hline GLM “static version" & 109.303 & 46.852 & 214,806 & 466.51 & 0.485 \\
(N=373,058) & $(5.43)^{* * *}$ & $(3.36)^{* * * *}$ & & & \\
GLM “dynamic version" & 115.371 & $\begin{array}{c}56.044 \\
(6.73)^{* * *}\end{array}$ & 174,374 & 460.17 & 0.573 \\
(N=258,900) & $(5.92)^{* * *}$ & $(6.374$ & \\
\hline
\end{tabular}

Section 5.B

\begin{tabular}{|c|c|c|c|c|c|c|}
\hline Two-Part Model & $\begin{array}{c}\text { IE } \\
\text { Severe } \\
\text { Obesity }\end{array}$ & $\begin{array}{c}\text { IE } \\
\text { Moderate } \\
\text { Obesity }\end{array}$ & $\begin{array}{c}\text { IE } \\
\text { Overweight }\end{array}$ & RMSE & MAPE & $\begin{array}{c}\text { Auxiliary } \\
\mathbf{R}^{\mathbf{2}}\end{array}$ \\
\hline $\begin{array}{l}\text { GLM "dynamic version" } \\
(\mathrm{N}=258,900)\end{array}$ & $\begin{array}{c}161.850 \\
(7.01)^{* * *}\end{array}$ & $\begin{array}{c}99.812 \\
(6.21)^{* * *}\end{array}$ & $\begin{array}{c}52.002 \\
(6.68) * * * \\
\end{array}$ & 174,296 & 459.96 & 0.573 \\
\hline
\end{tabular}

Notes: IE stands for incremental effect. Severe obesity: BMI $\geq 35 \mathrm{~kg} / \mathrm{m}^{2}$; moderate obesity: $30 \leq \mathrm{BMI}<35 \mathrm{~kg} / \mathrm{m}^{2}$; overweight: $25 \leq \mathrm{BMI}<30 \mathrm{~kg} / \mathrm{m}^{2}$; normal weight (reference category): $18.5 \leq \mathrm{BMI}<25 \mathrm{~kg} / \mathrm{m}^{2}$. Auxiliary $\mathrm{R}^{2}$ denotes the R-squared from a regression of actual costs on the predicted values; RMSE denotes the root mean squared error; MAPE is the mean absolute prediction error. Estimations account for an extensive list of covariates, health district dummies and time dummy variables. Regressions contain one-year lagged obesity/overweight rates. IEs have been bootstrapped (number of replications set at 200). $\mathrm{N}$ sample units refers to the second part. $* * * \mathrm{p}<0.01$; $* * \mathrm{p}<0.05 ; * \mathrm{p}<0.10$ 
Table 6. Increase in annual direct medical costs of severe and moderate obesity and overweight by gender and age (in Euros 2010). Panel data estimation

\begin{tabular}{|c|c|c|c|c|c|c|}
\hline Two-Part Model & $\begin{array}{l}\text { IE Severe } \\
\text { Obesity }\end{array}$ & $\begin{array}{l}\text { IE Moderate } \\
\text { Obesity }\end{array}$ & $\begin{array}{c}\text { IE } \\
\text { Overweight }\end{array}$ & RMSE & MAPE & $\begin{array}{c}\text { Auxiliary } \\
\mathbf{R}^{2}\end{array}$ \\
\hline $\begin{array}{l}\text { GLM "dynamic version". } \\
\text { Men sample }(\mathrm{N}=115,613)\end{array}$ & $\begin{array}{c}145.64 \\
(9.42)^{* * *}\end{array}$ & $\begin{array}{c}84.61 \\
(8.01)^{* * * *}\end{array}$ & $\begin{array}{c}43.49 \\
(7.34) * * *\end{array}$ & 115,958 & 457.55 & 0.563 \\
\hline $\begin{array}{l}\text { GLM "dynamic version" } \\
\text { Women sample }(\mathrm{N}=147,038)\end{array}$ & $\begin{array}{c}170.07 \\
(13.51)^{* * *}\end{array}$ & $\begin{array}{c}115.83 \\
(10.18)^{* * *}\end{array}$ & $\begin{array}{c}60.73 \\
(11.59) * * *\end{array}$ & 130,188 & 462.64 & 0.570 \\
\hline $\begin{array}{l}\text { GLM "dynamic version" } \\
\text { Below median age }(42) \\
(\mathrm{N}=118,180)\end{array}$ & $\begin{array}{c}87.34 \\
(16.07)^{* * *}\end{array}$ & $\begin{array}{c}63.79 \\
(10.41)^{* * *}\end{array}$ & $\begin{array}{c}31.74 \\
(6.04)^{* * *}\end{array}$ & 67,541 & 281.31 & 0.383 \\
\hline $\begin{array}{l}\text { GLM "dynamic version" } \\
\text { Above median age }(42) \\
(\mathrm{N}=124,231)\end{array}$ & $\begin{array}{c}209.90 \\
(15.95)^{* * *}\end{array}$ & $\begin{array}{c}118.10 \\
(11.15)^{* * *}\end{array}$ & $\begin{array}{c}52.31 \\
(9.45)^{* * *}\end{array}$ & 166,212 & 565.36 & 0.572 \\
\hline
\end{tabular}

Notes: IE stands for incremental effect. Severe obesity: BMI $\geq 35 \mathrm{~kg} / \mathrm{m}^{2}$; moderate obesity: $30 \leq \mathrm{BMI}<35 \mathrm{~kg} / \mathrm{m}^{2}$; overweight: $25 \leq \mathrm{BMI}<30 \mathrm{~kg} / \mathrm{m}^{2 ;}$ normal weight (reference category): $18.5 \leq \mathrm{BMI}<25 \mathrm{~kg} / \mathrm{m}^{2}$. Auxiliary $\mathrm{R}^{2}$ denotes the R-squared from a regression of actual costs on the predicted values; RMSE denotes the root mean squared error; MAPE is the mean absolute prediction error. Estimations account for an extensive list of covariates, health district dummies and time dummy variables. Regressions contain one-year lagged obesity/overweight rates. IEs have been bootstrapped (number of replications set at 200). N sample units refers to the second part. $* * * \mathrm{p}<0.01$; $* * \mathrm{p}<0.05 ; * \mathrm{p}<0.10$ 
Table 7. A robustness analysis: the increase in annual direct medical costs associated with (measured) BMI (in Euros 2010). Panel data estimation

Section 7.A

\begin{tabular}{lcccc}
\hline Two-Part Model & ME of BMI & RMSE & MAPE & $\begin{array}{c}\text { Auxiliary } \\
\mathbf{R}^{\mathbf{2}}\end{array}$ \\
\hline GLM "static version" (N=318,276) & $11.622(1.09)^{* * * *}$ & 333,482 & 457.39 & 0.534 \\
GLM "dynamic version" (N=258,900) & $10.404(2.06)^{* * *}$ & 257,508 & 501.13 & 0.627 \\
\hline
\end{tabular}

Section 7.B

\begin{tabular}{lcccc}
\hline Models & ME of BMI & RMSE & MAPE & $\begin{array}{c}\text { Auxiliary } \\
\mathbf{R}^{2}\end{array}$ \\
\hline $\begin{array}{l}\text { Single Equation Model } \\
\text { FE OLS log(costs) "dynamic version" } \\
\text { (N=318,276) }\end{array}$ & $6.733(1.33)^{* * * *}$ & 836,377 & $1,641.32$ & 0.329 \\
\hline $\begin{array}{l}\text { Sample Selection Model } \\
\text { GLM "dynamic version" (N=258,900) }\end{array}$ & $11.203(1.40)^{* * *}$ & 310,557 & 540.61 & 0.539 \\
\hline
\end{tabular}

Section 7.C

\begin{tabular}{lcccc}
\hline Two-Part Model & ME of BMI & RMSE & MAPE & $\begin{array}{c}\text { Auxiliary } \\
\mathbf{R}^{\mathbf{2}}\end{array}$ \\
\hline $\begin{array}{l}\text { GLM “dynamic version” } \\
\text { Obesity unrelated diseases (N=258,900) }\end{array}$ & $4.714(1.94)^{* * * *}$ & 257,187 & 500.28 & 0.621 \\
\hline $\begin{array}{l}\text { GLM “dynamic version” } \\
\text { 3+ BMI measurements (N=67,594) }\end{array}$ & $10.224(2.64)^{* * *}$ & 177,018 & 557.56 & 0.490 \\
\hline
\end{tabular}

Notes: ME stands for marginal effect. Auxiliary $\mathrm{R}^{2}$ denotes the R-squared from a regression of actual costs on the predicted values; RMSE denotes the root mean squared error; MAPE is the mean absolute prediction error. Estimations account for an extensive list of covariates, health district dummies and time dummy variables. MEs have been bootstrapped (number of replications set at 200). All regressions contain one-year lagged measured BMI. The Mundlak correction procedure is applied (with exception of the first model in Section 7.B). $* * * \mathrm{p}<0.01 ; * * \mathrm{p}<0.05 ; * \mathrm{p}<0.10$ 
Table 8. IV estimates: increase in annual direct medical costs of severe and moderate obesity and overweight (in Euros 2010). Panel data estimation

\begin{tabular}{|c|c|c|c|c|c|c|}
\hline Two-Part Model & $\begin{array}{c}\text { IE } \\
\text { Severe } \\
\text { Obesity }\end{array}$ & $\begin{array}{l}\text { IE Moderate } \\
\text { Obesity }\end{array}$ & $\begin{array}{c}\text { IE } \\
\text { Overweight }\end{array}$ & RMSE & MAPE & $\begin{array}{c}\text { Auxiliary } \\
\qquad \mathbf{R}^{2}\end{array}$ \\
\hline $\begin{array}{l}\text { GLM "dynamic version" } \\
\text { Non IV estimation }(\mathrm{N}=242,049)\end{array}$ & $\begin{array}{c}158.278 \\
(6.83) * * *\end{array}$ & $\begin{array}{c}96.804 \\
(6.24)^{* * * *}\end{array}$ & $\begin{array}{c}51.102 \\
(5.92)^{* * * *}\end{array}$ & 173,368 & 445.59 & 0.572 \\
\hline $\begin{array}{l}\text { GLM “dynamic version" } \\
\text { IV estimation }(\mathrm{N}=242,049)\end{array}$ & $\begin{array}{c}206.480 \\
(16.95)^{* * *}\end{array}$ & $\begin{array}{c}174.690 \\
(16.17)^{* * *}\end{array}$ & $\begin{array}{c}136.022 \\
(12.19)^{* * *}\end{array}$ & 174,247 & 461.10 & 0.571 \\
\hline
\end{tabular}

Notes: IE stands for incremental effect. Severe obesity: BMI $\geq 35 \mathrm{~kg} / \mathrm{m}^{2}$; moderate obesity: $30 \leq \mathrm{BMI}<35 \mathrm{~kg} / \mathrm{m}^{2}$; overweight: $25 \leq \mathrm{BMI}<30 \mathrm{~kg} / \mathrm{m}^{2}$; normal weight (reference category): $18.5 \leq \mathrm{BMI}<25 \mathrm{~kg} / \mathrm{m}^{2}$. Auxiliary $\mathrm{R}^{2}$ denotes the R-squared from a regression of actual costs on the predicted values; RMSE denotes the root mean squared error; MAPE is the mean absolute prediction error. Estimations account for an extensive list of covariates, health district dummies and time dummy variables. Regressions contain one-year lagged obesity/overweight rates. IEs have been bootstrapped (number of replications set at 200). $\mathrm{N}$ sample units refers to the second part. ${ }^{* * *} \mathrm{p}<0.01$; **p $<0.05 ; * \mathrm{p}<0.10$ 